\title{
CpG methylation of the PAl-I gene 5'-flanking region is inversely correlated with PAI-I mRNA levels in human cell lines
}

\author{
Shan Gao', Sune Skeldal', Annelise Krogdahl'2, Jens Ahm Sørensen³, Peter A. Andreasen' \\ 'Department of Molecular Biology, University of Aarhus, Aarhus C, Denmark \\ ${ }^{2}$ Departments of Pathology, and ${ }^{3}$ Plastic Surgery, Odense University Hospital, Odense, Denmark
}

\begin{abstract}
Summary
The physiological and pathophysiological functions of PAI-I are related to its expression by specific cell types in normal and diseased tissues. We analysed the contribution of DNA methylation to the variation in PAI-I mRNA levels in five cell lines. We found varying frequencies of methylation of $25 \mathrm{CpGs}$ in the $-805 /+152$ region of the PAl-I gene in Bowes, MCF-7 and U937 cells, while little or no methylation was detected in Hep2 and HT- 1080 cells. The methylation frequency was inversely correlated with PAI-I mRNA level within its 20-fold range in Bowes, MCF-7, U937, and Hep2 cells, while the lack of methylation in both Hep2 and HT1080 cells suggested another mechanism behind the 150 -fold higher level in HT-I080 cells than in Hep2 cells. However, all cell lines exhibited a high frequency of methylation of $10 \mathrm{CpGs}$ in a $C_{p}$ island at about -1800. Treatment with 5-aza-2'-deoxycyti-
\end{abstract}

\section{Keywords}

PAI-I, CPG methylation, histone acetylation, cell-specific, oral carcinoma dine led up to circa a 40-fold increase in the PAI-I mRNA level and a strong decrease in the frequency of methylation in the $-805 /+152$ region in Bowes, MCF-7 and U937. The histone deacetylase inhibitor trichostatin $A$ induced a several fold increase of the PAI-I mRNA level in cells with a high methylation frequency of the $-805 /+152$ region. As compared with matched normal tissue, three samples of oral squamous cell carcinomas displayed decreased frequencies of methylation of the PAI-I $5^{\prime}$ flanking region and increased levels of PAI-I mRNA. These results for the first time implicate DNA methylation and histone acetylation in regulation of the PAI-I gene, and indicate that without proper CpG islands in 5'-flanking region, trancription may be regulated by methylation of less dense CPGs in the 5'-flanking region rather than methylation of upstream $C_{p} G$ island.

\section{Introduction}

Plasminogen activator inhibitor-1 (PAI-1) regulates the activities of the plasminogen activators tPA and UPA (1), both serine proteases catalysing the conversion of the zymogen plasminogen to the active protease plasmin. Plasmin can degrade fibrin and other extracellular proteins (2). The relative blood plasma levels of tPA and PAI-1 determine the fibrinolytic capacity of blood (3). In humans, a high plasma PAI-1 level is a risk factor in myocardial infarction. Conditions with an increased risk of thrombotic disease, i.e., obesity, hypertension, insulin resistance, type-2 diabetes, and hypertriglyceridemia, are associated with elevated plasma PAI-1 levels. Interestingly, inhibitors of angiotensin converting enzyme decrease plasma PAI-1 levels and lead to reduction in ischemic events (3). Evidence for a direct causal role of PAI-1 in thrombotic events comes from the observation that transgenic mice with an increased plasma PAI-1 level develop venous and arterial occlusions. There is also evidence that PAI-1 contributes to pathological remodelling of the vascular wall and arteriosclerosis (3). uPA-catalysed plasmin generation has been implicated in the spread of cancerous diseases, plasmin-catalysed degradation of basement membranes believed to enable cancer cells to invade normal tissue. This idea is supported by evidence from model systems and by the observation that high tumour levels of uPA are correlated with poor prognosis in several cancers (2). Surprisingly, the PAI-1 levels in tumours are higher than in the corresponding normal tissue, and a high level of PAI-1 in tumours is an even better marker for a poor prognosis than the UPA level (4).

The physiological and pathophysiological roles of PAI-1 must be seen in relation to its cell-specific expression, which is again modulated by a large variety of hormones, cytokines, and growth factors (5). In normal humans and mice, a variety of cell types has been reported to express PAI-1, prominently 
adipocytes, hepatocytes and endothelial cells (5). In diseased tissues, an increased PAI-1 expression by specific cell types may be related to the pathogenesis. In the so-called metabolic syndrome, there seems to be an increased PAI-1 production by visceral adipose tissue, and the most important source of the elevated PAI-1 is from stromal cells, including monocytes and smooth muscle cells, not the adipocytes themselves. An elevation of the PAI-1 level in local endothelial cells and vascular smooth muscle cells has been shown to contribute to the thrombotic complications associated with plaque rupture in arteriosclerotic lesions found in kidney, liver and main arteries $(3,6)$. In several types of cancers, i.e., breast, prostate, and colon cancers, it was demonstrated that PAI-1 was expressed by several cell types, but the predominant PAI-1 expressing cell type was the myofibroblast, a cell type not present in the corresponding normal tissues (7-9).

The possibility that epigenetic mechanisms may contribute to cell-specific PAI-1 expression have caught our interest. One important mechanism for epigenetic regulation of gene transcription is silencing by methylation of $\mathrm{CpG}$ dinucleotides. $\mathrm{CpG}$ dinucleotides are underrepresented throughout genomes. Most CpGs ( 70\%) in mammalian genomes reside within repetitive elements and are methylated, probably as a mechanism for keeping these elements transcriptionally silent (10). In addition, there are so-called $\mathrm{CpG}$ islands, which are defined as stretches of DNA up to several $\mathrm{kb}$ in size that contain more than $6 \% \mathrm{CpG}$ dinucleotides of the total number of nucleotides. $\mathrm{CpG}$ islands are usually located at the $5^{\prime}$ end of genes, and approximately $50 \%$ of all genes contain one or more promoter-associated $\mathrm{CpG}$ islands. Originally, $\mathrm{CpG}$ islands were thought to be unmethylated in all normal tissues regardless of transcriptional status (10). However, now a number of methylated $\mathrm{CpG}$ islands have been identified in normal tissues. In these cases, including the maspin gene (11) and the $M C J$ gene (12), the degree of methylation shows an inverse correlation with the transcriptional activity of the genes in a cell or tissue-specific way. In tumours, epigenetic regulation of gene expression seems to play a major role. Aberrant hypermethylation in the silencing of tumour suppressor genes is well documented $(13,14)$. In addition, some genes are overexpressed in cancer cells due to non-methylated $\mathrm{CpG}$ islands. These genes include proto-oncogenes such as c-myc (15) and bcl-2 (16), synuclein $\gamma$ in breast carcinoma and ovarian carcinoma (17), $M A O B$ in human colonic adenocarcinoma (18), $M M P-9$ in lymphomas (19), MDR1 in acute myeloid leukemia (20), MAGE-1 in melanomas (21), and $u P A$ in malignant breast and prostate tissues $(22,23)$.

In order to initiate an analysis of the possible contribution of $\mathrm{CpG}$ methylation to the variation in cellular expression of the PAI-1 gene in normal and diseased tissues, we have now analysed the pattern of methylation of $\mathrm{CpG}$ dinucleotides around the start site of transcription of the PAI- 1 gene in 5 cell lines with a previously demonstrated more than 2000 -fold variation in PAI- 1 expression (24). We have found that methylation of $25 \mathrm{CpG}$ sites within approximately $900 \mathrm{bp}$ around the transcription initiation site but outside a proper $\mathrm{CpG}$ island is inversely correlated with the expression level of the gene, and provide evidence that silencing by methylation may act in conjunction with histone deacetylation.

\section{Materials and methods}

\section{Cell culture}

The cell lines HT-1080 (human fibrosarcoma cells, ATCC CCL 121), Hep2 (human laryngeal carcinoma cells, ATCC CCL 23), MCF-7 (human breast cancer cells, ATCC HTB 22), and Bowes (human melanoma cells, ATCC CRL 9607) were cultured in Dulbecco's modified Eagle's medium (DMEM). The cell line U937 (human histiocytic lymphoma cells, ATCC CRL 1593) was cultured in RPMI 1640 medium. The media were supplemented with $10 \%$ fetal bovine serum (FBS), $100 \mathrm{IU} / \mathrm{ml}$ penicillin, and $100 \mu \mathrm{g} / \mathrm{ml}$ streptomycin. The cells were grown at $37^{\circ} \mathrm{C}$ in humidified air containing $5 \% \mathrm{CO}_{2}$.

\section{5-aza-2'- deoxycytidine and trichostatin A treatment of cells}

Cells $\left(0.5 \times 10^{6}\right)$ were seeded in $10 \mathrm{~cm}$ tissue culture dishes in $10 \mathrm{ml}$ of standard medium. For a dose-response study, 5-aza-2'deoxycytidine (5-aza-CdR) (Sigma) was added at day 1 (at $~ 50 \%$ confluency), with final concentrations of $0.5,1,2$, and $5 \mu \mathrm{M}$. The medium was changed every day. At day 4 , cells were harvested for analysis. Time course studies were performed by incubating cells with $5 \mu \mathrm{M} 5$-aza-CdR for 1,2 , or 3 days, respectively (for U937 cells, $1 \mu \mathrm{M}$ 5-aza-CdR was used). In some cases, trichostatin A (TSA) (Sigma) was added at day 3 at a final concentration of $0.5 \mu \mathrm{M}(25)$.

The harvested cells were separated in two parts, one for preparation of DNA (DNeasy Tissue Kit, Qiagen) and one for preparation of cytoplasmic RNA (RNeasy Mini Kit, Qiagen). Oncolumn DNase digestion by RNA-free DNase I (Qiagen) was performed during the RNA purification procedure.

\section{Oral squamous cell carcinoma samples and matched normal tissues}

Laser microdissected, unfixed frozen samples from three oral squamous cell carcinomas and matched adjacent normal tissues from the same patient were obtained from Odense University Hospital, Denmark as previously described (26). All three patients were men, aged 61,65 , and 69 years, and the tumours were located at floor, tongue and inferior alveolar ridge, respectively.

\section{In silico analysis for CpG islands}

The genomic PAI-1 sequence (GeneBank Accession No. NM_000602) was screened for CpG islands, by the use of two CpG plot programmes (http://www.ebi.ac.uk/emboss/cpgplot/) and (http://www.ucsf.edu/urogene/methprimer/index1.html), with the following parameters: 100 bp length, $50 \% \mathrm{G}+\mathrm{C}$ and 0.6 observed/expected ratio, where "observed" is the observed number of $\mathrm{CpG}$ sites and "expected" equals (number of Cs * number of Gs)/window length.

\section{Methylation-specific PCR (MS-PCR)}

Genomic DNA was treated with sodium bisulfite as previously described (26). The primer sequences used for methylation-specific PCR (MS-PCR) analysis of the PAI-1 5'-flanking region are listed in Table 1. PCR reaction mixtures $(25 \mu \mathrm{l})$ contained 10 $\mathrm{pmol} / \mu \mathrm{l}$ of each primer, covering +10 to $+129,0.2 \mathrm{mM}$ of each dNTP, 1 x PCR buffer and 1 unit of HotStarTaq DNA polymerase 
(Qiagen), $0.2 \mathrm{mM}$ cresol red, 12\% (w/v) sucrose, and 50-100 ng of bisulfite-treated DNA(26). Reactions were started with initial denaturation at $95^{\circ} \mathrm{C}$ for $10 \mathrm{~min}$, followed by 35 cycles at $95^{\circ} \mathrm{C}$ for $30 \mathrm{~s}$, the appropriate annealing temperature for $30 \mathrm{~s}$ and $72^{\circ} \mathrm{C}$ for $30 \mathrm{~s}$. The annealing temperatures for the unmethylated and methylated reactions were $55^{\circ} \mathrm{C}$ and $57^{\circ} \mathrm{C}$, respectively. The PCR products were resolved on $2 \%$ agarose gels. CpGenome ${ }^{\mathrm{TM}}$ universally methylated DNA (Chemicon International Inc., California, USA) served as the methylated positive control. This DNA is enzymatically methylated human male genomic DNA.

\section{Bisulfite sequencing}

Bisulfite sequencing was performed as described elsewhere (17, 18). PCR amplification was performed in $25 \mu \mathrm{l}$ of reaction mixture containing $100 \mathrm{ng}$ bisulfite-treated DNA, $10 \mathrm{pmol} / \mu \mathrm{l}$ of each primer (Table 1), $0.2 \mathrm{mM}$ of each dNTP, $1 \mathrm{x}$ PCR buffer and 1 unit of HotStarTaq DNA polymerase (Qiagen). For amplification of SqProx, a $431 \mathrm{bp}$ sequence in the proximal region of the PAI-1 gene from -278 to +152 , the reaction was started with initial denaturation at $95^{\circ} \mathrm{C}$ for $10 \mathrm{~min}$, followed by 35 cycles at $95^{\circ} \mathrm{C}$ for $1 \mathrm{~min}, 55^{\circ} \mathrm{C}$ for $1 \mathrm{~min}$ and $72^{\circ} \mathrm{C}$ for $2 \mathrm{~min}$. For amplification of SqDistal, a $537 \mathrm{bp}$ sequence in the distal region from -805 to -268 , the reaction was started with initial denaturation at $95^{\circ} \mathrm{C}$ for $10 \mathrm{~min}$, followed by 40 cycles at $95^{\circ} \mathrm{C}$ for $1.5 \mathrm{~min}, 57^{\circ} \mathrm{C}$ for $1 \mathrm{~min}$ and $72^{\circ} \mathrm{C}$ for $2.5 \mathrm{~min}$. For amplification of the upstream $\mathrm{CpG}$ island, the reaction was performed by using the programme for MSP described above; the annealing temperature was $57^{\circ} \mathrm{C}$. Amplified DNA was subcloned into the vector pCR2.1 by using a One Shot Electroporation TOPO TA cloning kit (Invitrogen) and sequenced using the Dynamic ${ }^{\mathrm{TM}} \mathrm{ET}$ terminator cycle sequencing kit (Amersham Pharmacia Biot) and a 373A ABI sequencer (Applied Biosystems). For analysis of the upstream $\mathrm{CpG}$ island, the $\mathrm{PCR}$ product was gel purified before it was subcloned (Gel Extraction Kit, Qiagen). Ten positive clones were analysed for each sample. The frequency of methylated $\mathrm{CpG}$ sites (FMS) was calculated as (number of methylated $\mathrm{CpG}$ sites/ $25 \mathrm{CpG}$ sites)x $100 \%$. The frequency of total methylated CpGs (FTM) was calculated as (number of methylated CpGs /number of totally detected CpGs)x $100 \%$.

\section{Quantitative real-time RT PCR}

Reverse transcription reaction was performed with $2 \mu \mathrm{g}$ DNAfree RNA, using First-strand cDNA Synthesis Kit (Amersham). Quantitative real-time RT PCR was performed according to the instruction of the manufacturer. The primer sequences are shown in Table 1. The amplification reaction for quantitative real-time RT PCR was carried out in a final volume of $25 \mu$, containing $2 \mathrm{x}$ Brilliant Multiplex Master Mix (Stratagene). The comparative CT (threshold cycle) method described in the manufacturer's protocol was used to quantitate the relative PAI-1 mRNA expression level, comparing treated samples to concordant untreated controls. Thermal conditions were as follows: $95^{\circ} \mathrm{C}$ for 10 minutes to activate the DNA polymerase, then 40 cycles at $95^{\circ} \mathrm{C}$ for $30 \mathrm{~s}, 62^{\circ} \mathrm{C}$ for $30 \mathrm{~s}$, and $72^{\circ} \mathrm{C}$ for $30 \mathrm{~s}$. Amplification was performed on a Mx $4000^{\circledR}$ Multiplex Quantitative PCR System (Stratagene). The glyceraldehyde 3-phosphate dehydrogenase $(G A P D H)$ gene mRNA was amplified as an internal control to normalise the data of the PAI-1 mRNA level. All PAI-1 mRNA levels were expressed relative to the PAI-1 mRNA in the cell line HT-1080, which has a high PAI-1 expression and was run as a positive control in each reaction.

\section{Statistical analysis}

The effect of 5-aza-CdR on methylation was analysed with $x^{2}$ test. All analyses for effects of 5-aza-CdR and TSA on PAI-1 mRNA by quantitative real-time RT PCR were performed at least three times and presented the mean \pm SD. Paired-t test was performed for comparing the effects of 5-aza-CdR and TSA.

Table I: Primer sequences for MSP, bisulfite sequencing and real-time RT PCR.

\begin{tabular}{|c|c|c|c|c|}
\hline Primers & Primer sequence & Position & Annealing Temperature & Product size \\
\hline \multicolumn{5}{|l|}{ MSP } \\
\hline M-Forward & TGTTTGGTTGTAGGGTTAAGAGC & +9 & $57^{\circ} \mathrm{C}$ & $|2|$ \\
\hline M-Reverse & AAATACCTTACGATTAACGATTCGT & +129 & & \\
\hline U-Forward & GTTTGGTTGTAGGGTTAAGAGTGT & +10 & $55^{\circ} \mathrm{C}$ & 119 \\
\hline U-Reverse & AATACCTTACAATTAACAATTCATC & +128 & & \\
\hline \multicolumn{5}{|l|}{ Bisulfite sequencing } \\
\hline SeqProx-Forward & TAGGTAGAGGGTAGAAAGGTTAAGG & -278 & $55^{\circ} \mathrm{C}$ & 431 \\
\hline SeqProx-Reverse & СТТТТСТССТАССТААААТТСТСАААAА & +152 & & \\
\hline SeqDistal-Forward & TTTTTATTATGGTAATTTTTGGTTT & -805 & $57^{\circ} \mathrm{C}$ & 537 \\
\hline SeqDistal-Reverse & СССТСТАССТАТАТСТАТСТСТССС & -268 & & \\
\hline SeqCpGisland-Forword & TGTTAAAATTTTAAATTTAGTTGGG & -1936 & $57^{\circ} \mathrm{C}$ & 216 \\
\hline SeqCpGisland-Reverse & САAАТАAТTСТССТАССТСААССТС & -1721 & & \\
\hline \multicolumn{5}{|l|}{ Q-RT-PCR } \\
\hline PAI-IRT- Forward & GAGGTGCCTCTCTCTGCCCTCACCAACATT & +925 & $62^{\circ} \mathrm{C}$ & 184 \\
\hline PAI-IRT- Reverse & AGCCTGAAACTGTCTGAACATGTCG & +1108 & & \\
\hline GAPDH- Forward & GGTCGGAGTCAACGGATTT & +72 & $62^{\circ} \mathrm{C}$ & 258 \\
\hline GAPDH- Reverse & CCAGCATCGCCCCACTTGA & +329 & & \\
\hline
\end{tabular}




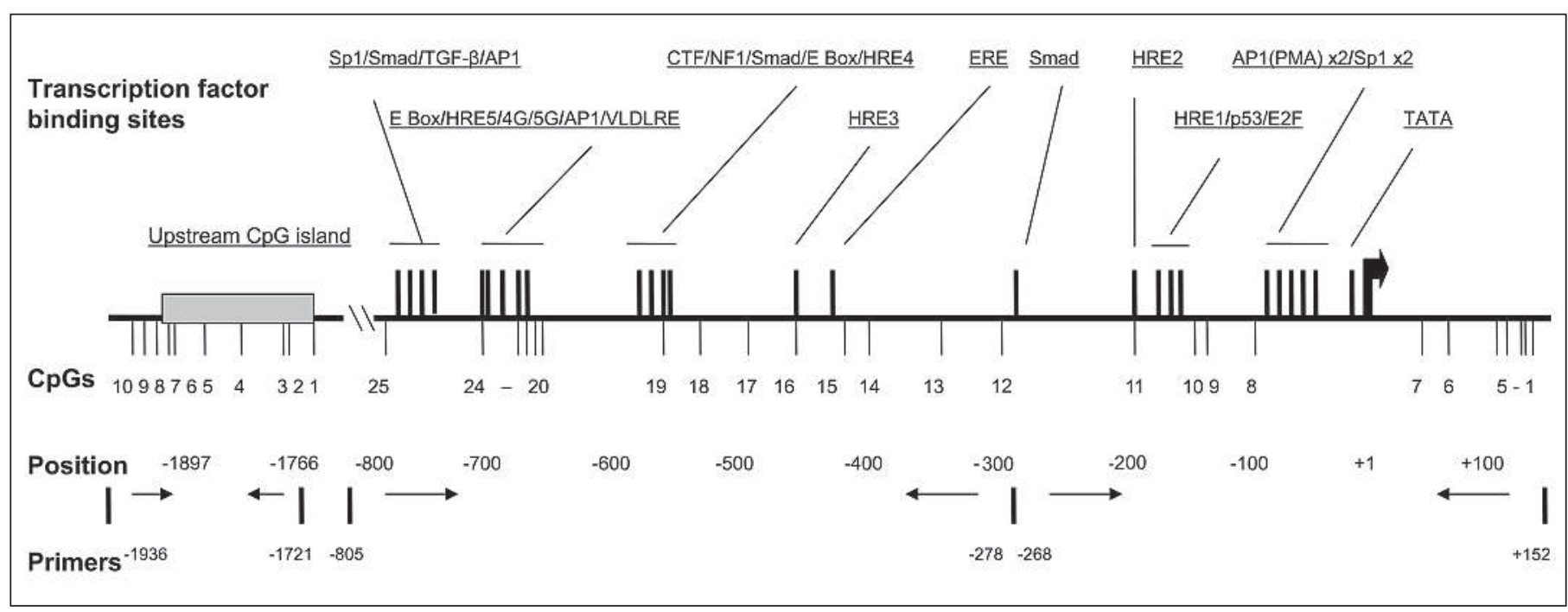

Figure I: CpG sites and known binding sites for transcription factors in the human PAI-I gene 5'-flanking region. The transcription initiation site $(+I)$ and the TATA box are indicated. The known transcription factor binding sites are indicated by vertical bars pointing upwards. The $25 \mathrm{Cp}_{\mathrm{p}}$ sites in the 5'-flanking region (-805 to +152) and 10 CPG sites in the upstream region $(-1936$ to -1721$)$ are indicated by thin vertical bars pointing downward and numbered under the line. The filled box indicates the upstream CPG island. At the bottom of the figure, the bisulfite sequencing primers' positions are indicated by arrows. The following transcription factor binding sites are known: three SpI binding sites, at $-766,-73$, and -42 , mediating PAI-I gene regulation by glucose,

\section{Results}

\section{CpG sites in the PAl-I gene}

The human PAI-1 gene is localised on chromosome 7q22.1 (27). We screened the genomic PAI-1 sequence (GeneBank Accession No. NM_000602) for CpG islands. Initially, we screened an interval of $1 \mathrm{~kb}$ upstream and $1 \mathrm{~kb}$ downstream from the transcription initiation site. In the region from -805 to +152 , spanning the PAI-1 5'-flanking region and the first exon, and containing binding sites for a number of transcription factors implicated in regulation of PAI-1 gene transcription $(5,28)$ (Fig. 1), we found 25 $\mathrm{CpG}$ dinucleotides, which we will refer to a $\mathrm{CpG} \# 1$ to \#25, beginning from the 3 'end. However, no typical $\mathrm{CpG}$ island was identified. Although smaller and less $\mathrm{CpG}$-rich than proper $\mathrm{CpG}$ islands, two short sequences were seen to have a relatively high density of CpGs. Thus, there were five CpGs (\#24 to \#20) from -679 to -639 , which has been referred to as a GC-rich sequence previously (29), and five CpGs ( $\# 5$ to $\# 1$ ) from +91 to +121 . When we extended our search to $2 \mathrm{~kb}$ upstream and $2 \mathrm{~kb}$ downstream from the transcription initiation site, one small $\mathrm{CpG}$ island was found, covering -1897 to -1766 (132 bp) and containing $7 \mathrm{CpG}$ sites. We will refer to it as the upstream $\mathrm{CpG}$ island. By screening this sequence and its flanking sequences manually, we identified a total of $10 \mathrm{CpGs}$ between -1936 and -1721 (Fig. 1). There were no $\mathrm{CpG}$ islands up to $2 \mathrm{~kb}$ downstream of the transcription start site. fatty acid and angiotensin II $(5,42)$; four API binding sites , at -72 I, $-662,-79$, and -58 (the latter two covering a phorbol ester response element) (38); five hypoxia-responsive elements (HRE) at $-676,-566$, $-452,-195$ and -161 (5, 43); a very low density lipoprotein-responsive element (VLDLRE) at -672 to -657 (44) ; the $4 \mathrm{G} / 5 \mathrm{G}$ polymorphism at -675 (42); SMAD 3 and 4 protein-binding sites mediating TGF- $\beta$ responsiveness at $-730,-580$, and -280 (42); consensus binding sites for the CTF/NFI (CCAAT-binding transcription factor /nuclear factor-I) at -598 to -532 ; an estrogen response element (ERE) at -427 to -407 ; a p53-responsive element at -159 to -134 , overlapping with a binding site for a PAI-I negative regulator $E_{2} F(5)$; two $E$ boxes at $-68 I$ and -565 (45).

\section{Cell lines with different levels of PAI-I expression}

To analyse the impact of $\mathrm{CpG}$ methylation on the expression of the PAI-1 gene, we chose five cell lines, HT-1080, Hep2, U937, MCF-7 and Bowes, which were previously shown to have highly variable levels of PAI-1 expression, as evidenced by ELISA measurements of PAI-1 protein levels in their conditioned media (24). The variable level of PAI-1 expression was confirmed by analysis of PAI-1 mRNA expression. Real time RT-PCR results showed variations in PAI-1 mRNA levels similar to the previously reported variations in PAI-1 protein levels in the five cell lines. Compared with HT-1080, the relative PAI-1 mRNA expression levels of Hep2, U937, MCF-7 and Bowes were around 1/150, 1/600, 1/1800 and 1/3300, respectively (Fig. 2).

\section{Analysis of CpG methylation in the cell lines by MSP analysis and bisulfite sequencing}

To investigate whether the PAI-1 expression level was correlated with the methylation status of $\mathrm{CpG}$ dinucleotides located at 5' region of the PAI-1 gene, methylation analysis was performed by both MSP and bisulfite sequencing. By MSP analysis with primers covering +10 to +129 , CpG methylation was found in Bowes, MCF-7, and U937. The signal obtained with the primers for methylated DNA was stronger than the signal obtained with the primers for unmethylated DNA in Bowes and MCF-7 cells, while the opposite pattern was seen in U937, indicating that the frequency of methylation was much higher in Bowes and MCF-7 than in U937 cells. However, no methylation was observed in Hep2 and HT-1080 cells (Fig. 3). The methylation status was in- 
versely correlated with the PAI-1 mRNA expression level among the different cell lines (Fig. 2).

Bisulfite sequencing was performed for the region from -805 to +152 , containing $25 \mathrm{CpG}$ dinucleotides, and for the region from -1936 to -1721 , containing $10 \mathrm{CpGs}$ (Fig. 1). Two pairs of primers were used for amplifying the $958 \mathrm{bp}$ sequence from -805 to +152 , one covering $\mathrm{CpG} \# 1$ to $\# 11$, which will be referred to as the proximal region, and another covering $\mathrm{CpG} \# 12$ to \#25, which will be referred to as the distal region. The analysis showed different frequencies of methylation in the different cell lines (Fig. 4). Methylation was observed at 25, 18, and 12 of the $25 \mathrm{CpG}$ sites in Bowes, MCF-7 and U937 cells, respectively, corresponding to a frequency of methylated $\mathrm{CpG}$ sites (FMS) of $100 \%, 72 \%$ and $48 \%$, and a frequency of total methylated CpGs (FTM) of 66\%, 44\% and 20\%, respectively (Table 2). In particular, CpGs \#1 to \#4, \#7, \#13 and \#15 were methylated in all investigated clones from Bowes cells, while $\mathrm{CpG} \# 1, \# 2$, \#7, and \#15 were methylated in all investigated clones from MCF-7 cells. Methylation at $\mathrm{CpG}$ sites \#1 to \#5, \#20 and \#21, included in two clusters with relative high $\mathrm{CpG}$ density, was observed in all three cell lines. CpG methylation was only found at two CpG sites (\#1 and \#20) in 2 of 10 different clones in Hep2 cells, while no methylation was observed in HT-1080 cells.

Surprisingly, methylation was found in all five cell lines at all CpG sites in the upstream CpG island at -1936 to -1721 (Fig. 4). Especially, the frequency of methylation in HT-1080 and Hep2 cells, with high and moderate PAI-1 expression, was not significantly different from that in Bowes, MCF-7, and U937 cells, with low PAI-1 expression.

\section{Effect of 5-aza-CdR and TSA treatment on PAI-I expression levels in the cell lines}

We analysed the effect of 5-aza-CdR treatment on the methylation pattern of the PAI-1 gene and on the PAI- 1 mRNA expression in U937, MCF-7 and Bowes cells. By MSP analysis, we observed a time- and dose-dependent alteration in the methylation pattern, consisting in a decreased intensity of the band obtained with the primers for methylated DNA, but an increased intensity with the primers for unmethylated DNA (Fig. 5). By bisulfite sequencing, 5-aza-CdR treatment was found to result in demethylation of most of $\mathrm{CpGs}$ in the -805 to +152 region in all three cell lines (Table 2, Fig. 4). In Bowes, 5-aza-CdR treatment resulted in complete demethylation of CpGs \#6-\#11, \#16, \#17, $\# 19$, \#24, and \#25, while incomplete demethylation was found at the other CpGs, except for $\mathrm{CpG} \# 12$, the methylation of which was not affected by the treatment. In MCF-7 cells, there was no change in the number of methylated $\mathrm{CpG}$ sites, but the frequency of methylation at each site decreased, and two of the analysed clones lacked methylation at CpGs \#1 - \#11. In U937 cells, the treatment resulted in complete demethylation at $\mathrm{CpG}$ sites \#2, $\# 3$, \#4, \#13, \#14, \#18, and \#21, and incomplete demethylation at other $\mathrm{CpG}$ sites, except $\# 15$, the methylation of which was not affected. Thus, the frequency of methylated CpG sites (FMS) and the frequency of total methylated CpGs (FTM) decreased in all three cell lines, and there was a decrease in the frequency of methylation at most $\mathrm{CpG}$ sites, especially in the proximal region. Totally, by comparing the frequency of total methylated CpGs (FTM) between untreated and 5-aza-CdR treated cells, a signifi-

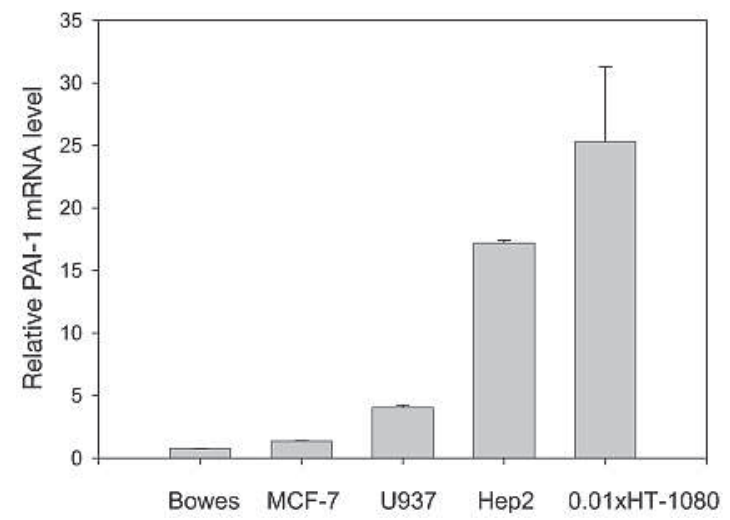

Figure 2: PAI-I mRNA expression of five cell lines, analysed by real time RT-PCR. Compared with HT-I080, the PAI-I mRNA expression level of Hep2, U937, MCF-7 and Bowes was only I/I50, I/600, I/I800 and I/3300, respectively. All data for real-time RT PCR were normalized against the level of internal control, GAPDH mRNA, and repeated three times, then presented as mean \pm SD.

cant decrease was found, from $43.6 \%$ to $15.5 \%$ when data from all cells were pooled $(\mathrm{p}<0.001)$ (Table 2$)$.

Representative experiments on the dose-dependence and time-course of 5-aza-CdR effect on PAI-1 mRNA level, as analysed real time RT-PCR were shown in Figure 5. We observed $1.5,2,9$ and 17 fold increase of the relative PAI- 1 mRNA level by 3 days' treatment of MCF-7 cells with 5-aza-CdR in 0.5, 1.0, 2.0, and $5.0 \mu \mathrm{M}$ concentrations, respectively; and 6-, 15- and 33-fold increase by treatment of Bowes cells with $5.0 \mu \mathrm{M} 5$-aza-CdR for 1, 2, and 3 days, respectively (Fig. 5). Treatment of 5-aza-CdR for 3 days also caused a 5-fold increase of the PAI-1 mRNA level in U937 cells, but had no significant effect on the PAI-1 mRNA level in Hep2 cells (Fig. 6).

It has become clear that deacetylation of histones is also involved in the gene silencing and may play a role associated with that of DNA methylation (30). We therefore also examined the potential role of histone acetylation in the regulation of the PAI-1 gene expression, using treatment with TSA, a histone deacety-

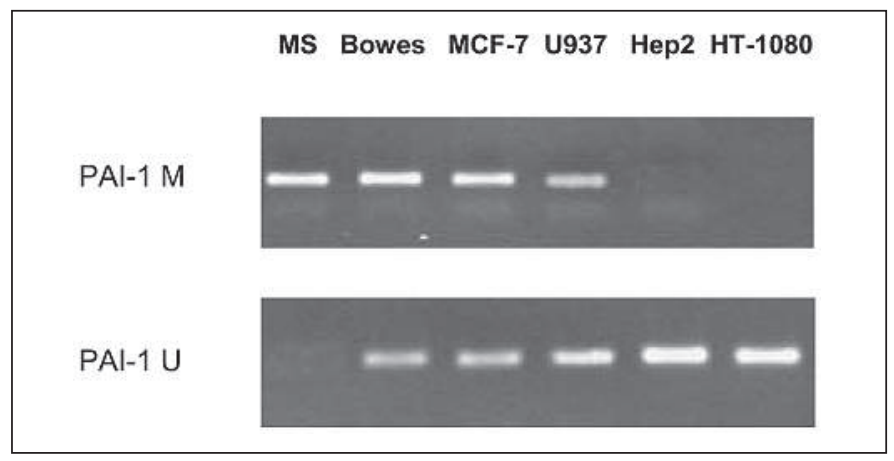

Figure 3: MSP analysis of the PAI-I 5'-flanking region in five cell lines. Genomic DNA was treated with sodium bisulfite and PCR-amplified with primer pairs, covering CpGs \#7 to \#I at the +9 to +129 region, specific for methylated $(M)$ and unmethylated $(U)$ PAI-I alleles. Methylated DNA (MS) (CpGenome ${ }^{T M}$ Universal Methylated DNA) from Chemicon International, Inc., was a positive control. 
Bowes

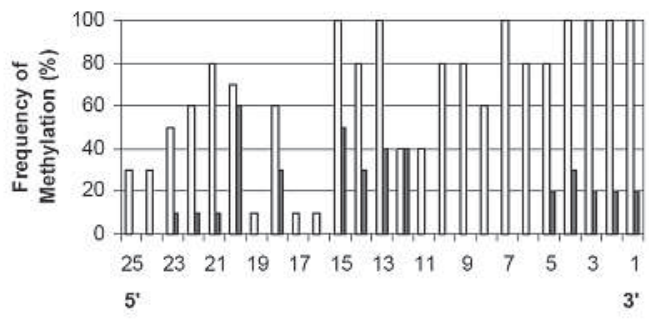

MCF-7

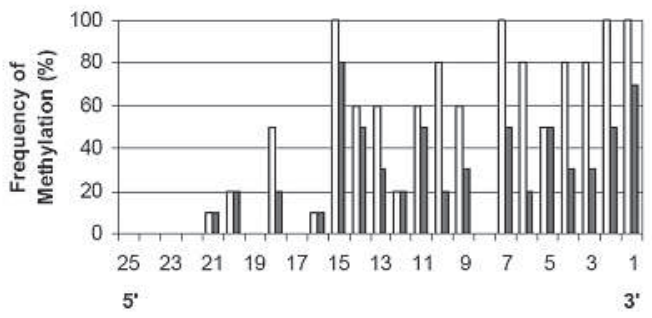

U937

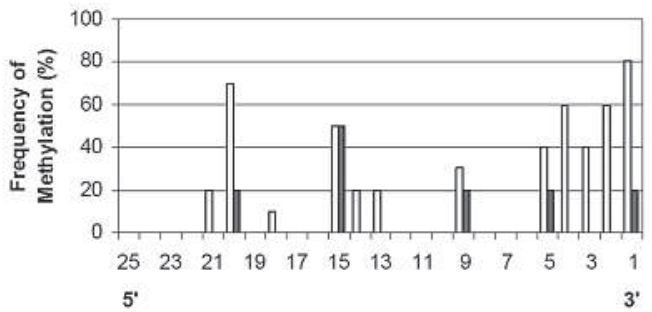

Hep2

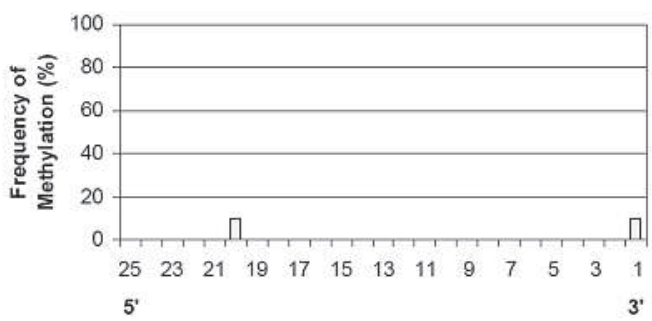

HT -1080

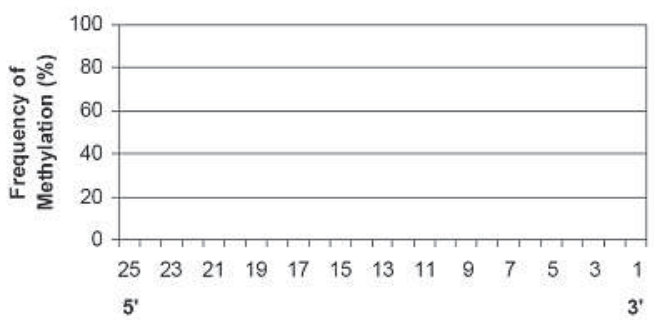

Bowes

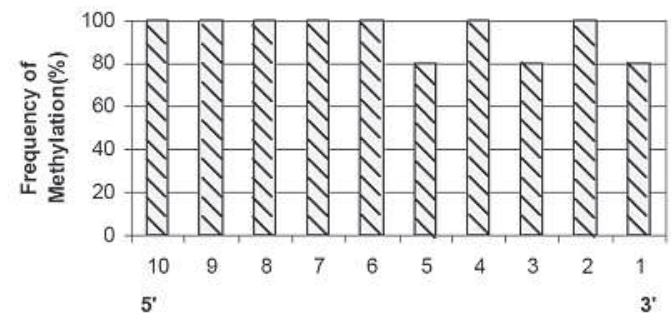

MCF-7

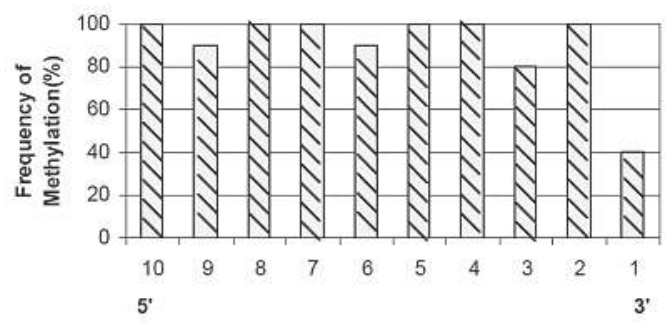

U937

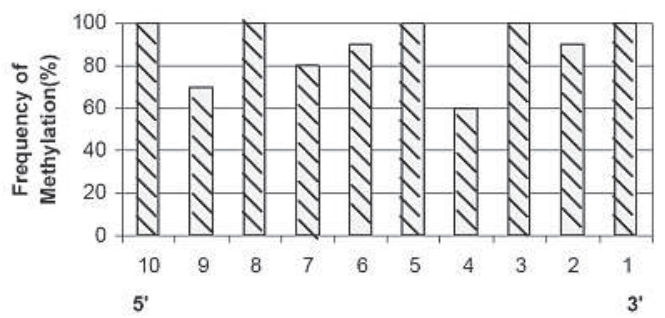

Hep2

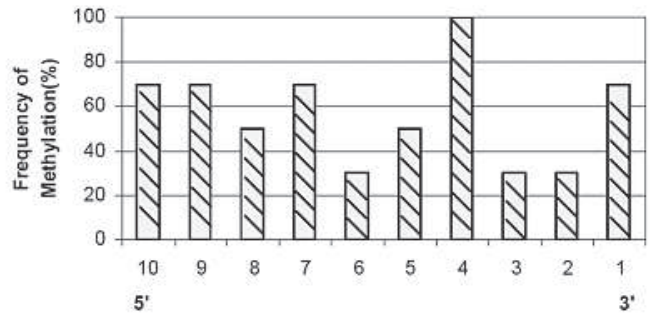

HT-1080

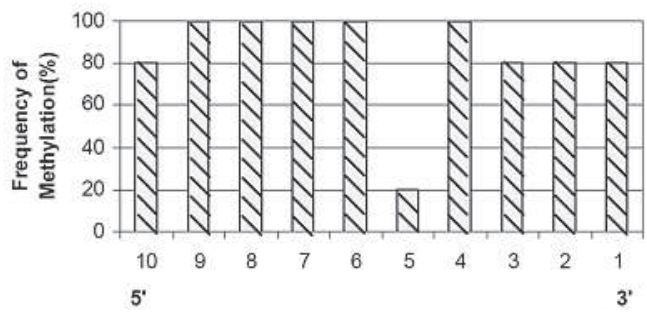

Figure 4: Bisulfite sequencing analysis of CpG methylation in five cell lines. Left column, analysis of the $25 C_{p G}$ sites in the -805 to +152 region of th PAI-I gene; right column, analysis of the 10 CPG sites in the -1936 to - I72I region. The results shown were obtained with a single DNA preparation, and a similar frequency $( \pm 10 \%)$ could be seen in at least one other DNA preparation. Unfilled bars, untreated cells; filled bars, 3 days' 5 -aza-CdR treated cells. The bars represent the frequency of methylation at each particular CpG site, numbered as indicated in figure I. 
Table 2: Comparison of the frequency of methylation in the PAI-I 5'-flanking region in three cell lines with or without 5-aza-CdR treatment.

\begin{tabular}{|c|c|c|c|}
\hline & Cells & FMS - $\%$ & FTM - \% \\
\hline \multirow[t]{2}{*}{ Bowes } & Untreated & 100 & 66 \\
\hline & 5-aza-CdR & $56 * *$ & $15^{* *}$ \\
\hline \multirow[t]{2}{*}{ MCF-7 } & Untreated & 72 & 45 \\
\hline & 5-aza-CdR & 72 & $25^{*}$ \\
\hline \multirow[t]{2}{*}{ U937 } & Untreated & 48 & 20 \\
\hline & 5-aza-CdR & $20^{* * *}$ & $5.2^{2 * *}$ \\
\hline \multicolumn{4}{|c|}{ Total for all three cell lines } \\
\hline & Untreated & 72 & 43.6 \\
\hline & 5-aza-CdR & $48 *$ & $15.5^{* *}$ \\
\hline
\end{tabular}

lase inhibitor, with or without simultaneous treatment with 5-aza-CdR (Fig. 6). We found that TSA treatment caused a $6-$ and 8-fold increase of the PAI-1 mRNA level in MCF-7 and Bowes, respectively, which had a high frequency of methylation of the -805 to +152 region, but no or only a modest increase in cells with a lower frequency of methylation, U937 and Hep2. These results indicated that the histone acetylation status was also implicated in the control of transcription of the PAI-1 gene, particularly in cells with a high level of $\mathrm{CpG}$ methylation of the PAI-1 5'-flanking region.

\section{PAI-I gene 5'-flanking region methylation and mRNA expression in oral carcinomas and matched normal tissues}

In order to evaluate whether variation in methylation frequency is also inversely correlated with PAI-1 expression in intact tissues, we analysed 3 samples of oral squamous cell carcinomas and matched normal tissues from the same patients. These 3 particular patients were chosen for analysis because the PAI-1 levels in the tumour tissue were 22-, 13-, and 12-fold higher than in the matched normal tissues (Fig. 7). CpG methylation of the PAI-1 gene 5'-flanking region was found in all three tumours and all three normal tissues, but the frequency of methylated $\mathrm{CpG}$ sites (FMS) was lower in the tumour samples than in the corresponding normal tissue samples, $16 \%$ vs $40 \%, 4 \%$ vs $24 \%$, and $8 \%$ vs $24 \%$, respectively (Fig. 7). Thus, there was an inverse correlation between methylation and expression also in these samples from tumours and intact tissues.

\section{Discussion}

The present results implicate for the first time $\mathrm{CpG}$ methylation in the regulation of $P A I-1$ gene transcription. No $\mathrm{CpG}$ island could be identified in the region from -805 to +152 relative to the transcription initiation site. Neither could any $\mathrm{CpG}$ island be identified up to $2000 \mathrm{bp}$ downstream of the transcription initiation site, but a small island was found at about $1800 \mathrm{bp}$ upstream. We observed that the degree of methylation of $25 \mathrm{CpG}$ dinucleotides in the $P A I-1-805$ to +152 region was inversely correlated with the level of PAI-1 mRNA in five different cell lines. Treatment of the cells with 5-aza-CdR resulted in demethylation
A

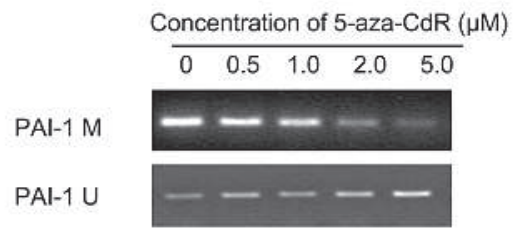

B

Time of $5 \mu \mathrm{M} 5$-aza-CdR treatment (days)

PAl-1 M \begin{tabular}{lllll}
\hline MS & 0 & 1 & 2 & 3
\end{tabular}

PAl-1 U

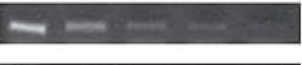

C

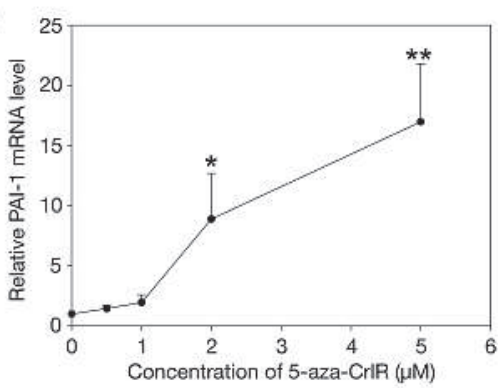

D

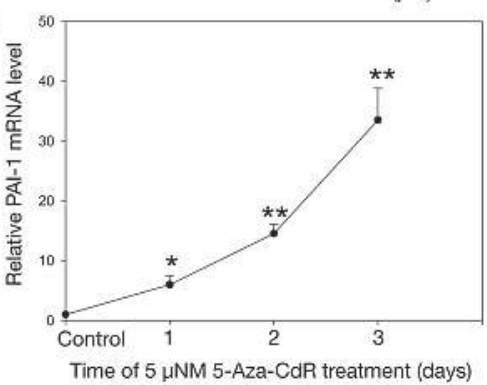

Figure 5: Dose-dependence and time-course of the effect of 5-aza-CdR treatment on methylation status of the PAI-I gene 5'-flanking region and on the PAI-I mRNA levels. A and C,

MCF-7 cells were treated with the indicated concentrations of 5-aza$\mathrm{CdR}$ for three days, then analysed for methylation status of the PAI-I 5 '-flanking region by MSP (A) and for the PAl-I mRNA levels by real time RT-PCR (C). B and D, Bowes cells were treated with $5 \mu \mathrm{M} 5$-aza$C d R$ for the indicated number of days, then analysed for methylation status of the PAl-I 5'-flanking region by MSP (B) and for the PAI-I mRNA levels by real time RT-PCR (D). C and D showed means \pm SD for 3 independent experiments and evaluated by Student t-test: * significantly different from untreated control, $p<0.05$, ** significantly different from untreated control, $\mathrm{p}<0.0 \mathrm{I}$. MS, methylated DNA control.

of the CpGs in the region and in increased levels of PAI-1 mRNA. In contrast, the methylation status of $10 \mathrm{CpGs}$ in the upstream CpG island was not correlated with the PAI-1 mRNA levels in the five cell lines. We therefore believe that we have strong arguments, although no proof, which support the notion that methylation of the CpGs in the 5'-flanking region and the first exon, but not of the far upstream $\mathrm{CpG}$ island, is causally involved in regulation of transcription of the PAI-1 gene. Proof will require demonstration that in vitro methylated 5'-flanking region drives transcription from a reporter gene less efficiently than non-methylated 5'-flanking region. 

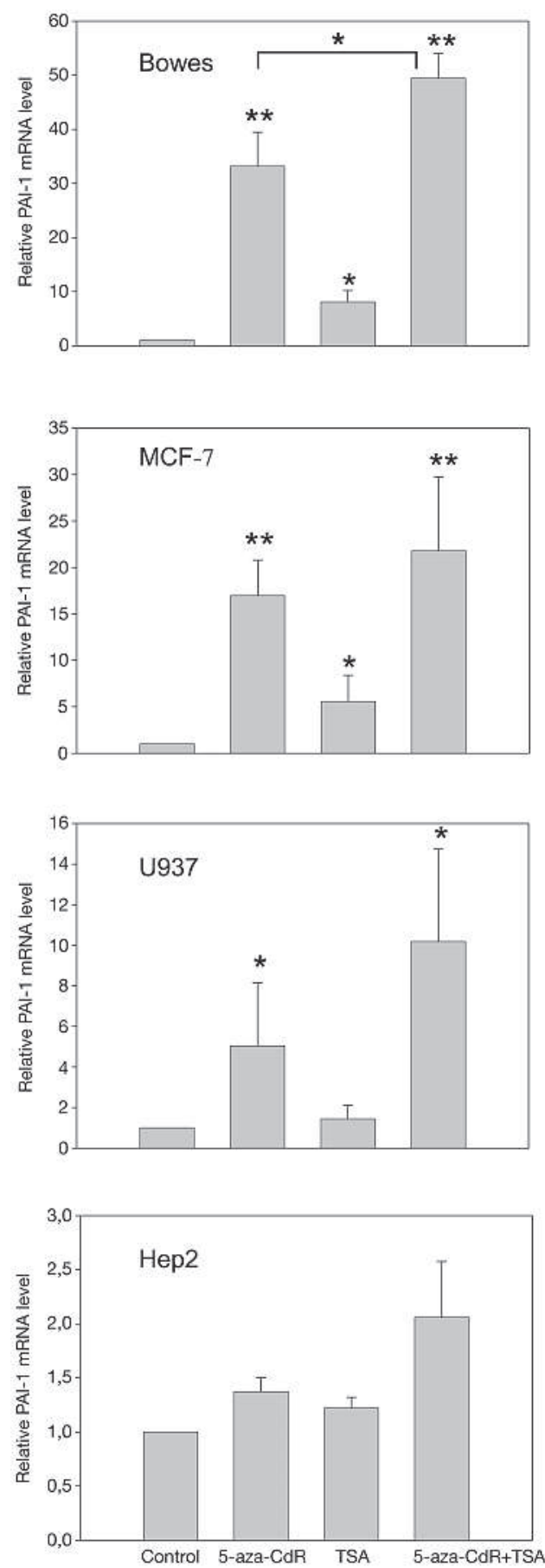

Figure 6: Effects of combined treatment with 5-aza-CdR and TSA on the PAI-I mRNA levels. The indicated cell lines were cultured for 3 days with or without $5.0 \mu \mathrm{M}$ 5-aza-CdR (I.0 $\mu \mathrm{M}$ for U937 cells), by which time the culture was continued for an additional day with or without $0.5 \mu \mathrm{MTSA}$. After harvest, the PAI-I mRNA levels were determined by real time RT PCR and normalised against the GAPDH mRNA levels. The figures showed means \pm SD for three independent experiments and evaluated by Student t-test: * significantly different from untreated control, $p<0.05$, ** significantly different from untreated control, $p<0.01$. By comparing the TSA effect after 5 -aza-CdR treatment for induction of the PAI-I mRNA expression, only in Bowes there was a significant difference between these two groups: " 5 -aza-CdR" and " 5 -azaCdR+TSA" $(p<0.05)$
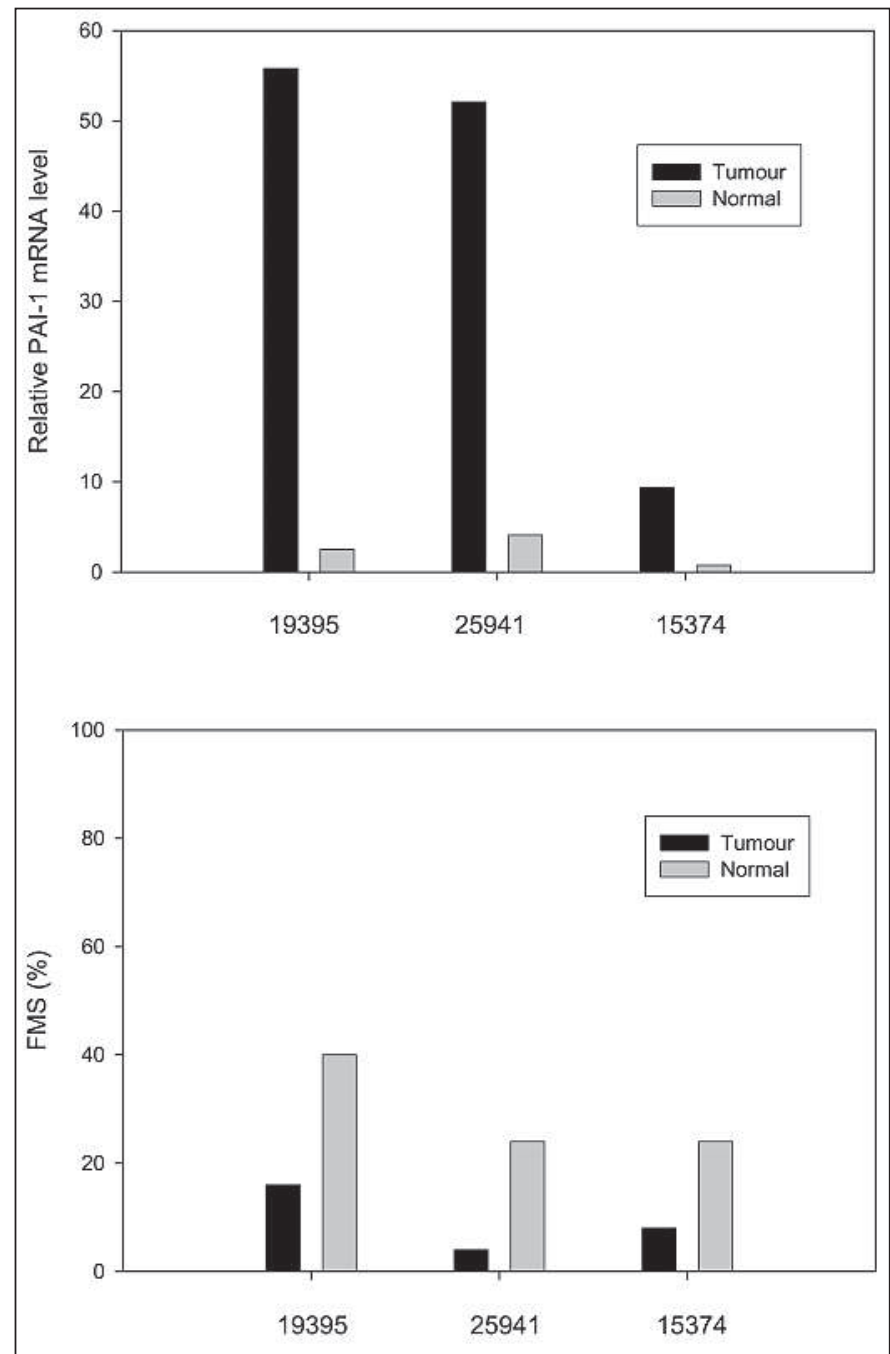

Figure 7: Methylation and relative PAI-I expression in three oral carcinomas and the corresponding normal tissues. The tissues were analysed for the relative PAI-I mRNA levels (top panel) and CPG methylation of the PAl-I gene 5'-flanking region (bottom panel). The CpG methylation frequency is given as FMS. Black columns represent results obtained with tumours, grey columns represent results obtained with normal tissues.

However, it is also clear that other mechanisms for transcriptional regulation are equally as important as the -805 to +152 region lacked methylation in both Hep2 and HT-1080 cells, which nevertheless had around 150-fold different levels of PAI-1 mRNA. Inspecting the PAI-1 mRNA levels in the different cell lines in the absence and presence of 5-aza-CdR, one may conclude that variations in $\mathrm{CpG}$ methylation are responsible for differences in expression of one to two orders of magnitude, like that between Bowes and Hep2 cells, while other, positively acting factors are important for the very high expression by HT-1080 cells.

Although DNA methylation in $\mathrm{CpG}$ islands is believed to play an important role in regulation of gene expression, it has been suggested that methylation of $\mathrm{CpG}$ islands localised at exonic sites with a great distance from the 5 '-flanking region cannot affect transcription $(12,31)$. Results from methylation 
studies of the $A B O$ gene (26) and the $h T E R T$ (32) gene also indicated that a close distance of a $\mathrm{CpG}$ island from transcription initiation site was necessary for gene regulation by methylation of the $\mathrm{CpG}$ island. Our present results are in agreement with such a hypothesis since we found that methylation of the upstream $\mathrm{CpG}$ island was not related to the PAI-1 gene expression. The small size of this $\mathrm{CpG}$ island may also contribute to its lack of importance, similarly to the suggestion about $\mathrm{CpG}$ island methylation of the p16 promoter and exon 2 region (33). In the absence of $\mathrm{CpG}$ islands close to the 5'-end of genes, methylation of less densely spaced $\mathrm{CpGs}$ in the promoter region may be more relevant to transcriptional regulation than $\mathrm{CpG}$ islands. It has previously been suggested that non-CpG island promoters of various genes undergo transcriptional activation by demethylation of specific sequences in a tissue-specific fashion (34). One recent report showed that DNA methylation also plays a role in control of $I L-4$ (interleukin-4) gene expression which exhibited only rare $\mathrm{CpG}$ sites in the promoter region: site-specific methylation of $5 \mathrm{CpG}$ sites within approximate $800 \mathrm{bp}$ promoter region was found more important than methylation of $\mathrm{CpGs}$ more than -900 bp away from the transcriptional initiation site (35). The p53 promoter does not contain a $\mathrm{CpG}$ island either, but alterations in $\mathrm{CpG}$ methylation in the $p 53$ promoter have been found to be site-specific and to vary with the stage of carcinogenesis. A critical single $\mathrm{CpG}$ site could work in initiation of de novo methylation, and progressive spreading of methylation was associated with transcriptional inactivation of the $p 53$ gene (36). One may consider whether an analogous situation exists with the PAI-1 gene, but we could not find such a critical CpG site in present study. As no typical CpG island was found in the PAI-1 promoter, the relative density of $\mathrm{CpG}$ sites may be important for regulating transcription. We found two $\mathrm{CpG}$ clusters containing relative higher density of $\mathrm{CpGs}$, i.e., five $\mathrm{CpGs}$ (\#24 to \#20) from -679 to -639 and five CpGs (\#5 to \#1) from +91 to +121 . In fact, we found a more frequent methylation of CpGs \#5 to \#1 than of the other CpGs in Bowes, MCF-7, and U937 cells, making it possible that methylation of the PAI-1 gene 5'-flanking region spreads from an initiation site to adjacent sites (12).

One possible mechanism by which $\mathrm{CpG}$ methylation may silence transcriptional activity is by directly preventing the binding of transcription factors to their DNA binding sites (10).To function in this way, it is necessary that the methylated $\mathrm{CpG}$ dinucleotides lie in or near the cis-acting regulatory elements. Methylation may be targeted to these particular regions through direct interaction with sequence-specific DNA-binding proteins, which furthermore may regulate cell-specific gene expression $(10,37)$. Previous studies of the PAI-1 gene 5'-flanking region showed that the region up to -805 contains a number of sequences involved in recognition of transcription factors and in regulation of transcriptional activity of the PAI-1 gene by hormones, cytokines, and growth factors (Fig. 1). As a result, transcriptional control of the PAI-1 gene is a pivotal mechanism in determining tissue and plasma PAI-1 content (38). In present study, the potentially methylated CpGs were mostly found outside the regulatory sequences identified so far. Potentially methylated CpGs were seen in the two E boxes overlapping with HRE-5 and HRE-4 (CACGTG, CpG \#24 and \#19), in HRE-3 and HRE-2 (CCACGTTT, CpG \#16 and ACACGTAC, CpG
$\# 11$ ), as well as the VLDLRE (GGAGTCAGCCGTGTATCATCG, CpG\#23 and\#22) (10). However, all these sites showed a relatively low methylation frequency, and it is therefore not at the present stage possible to make conclusions concerning a possible direct regulatory correlation between $\mathrm{CpG}$ methylation and transcriptional factor binding in the PAI-1 gene.

An alternative possibility for a mechanism by which $\mathrm{CpG}$ methylation may affect gene transcription is binding of methyl binding proteins to methylated $\mathrm{CpGs}$, which again attract histone deacetylases. Deacetylation of histone favours an inactive chromatin configuration (39). We found that an inhibitor of histone deacetylase, TSA, could increase the level of PAI-1 mRNA in cells with extensive methylation of the PAI-1 5'-flanking region, i.e., Bowes and MCF-7 cells, while there was little or no effect in cells with less extensive methylation, i.e., U937 and Hep2 cells. Likewise, there was little or no effect of TSA in 5-aza-CdR treated Bowes and MCF-7 cells. Our observation with TSA is in agreement with the concept that methylated $\mathrm{CpGs}$ attract histone deacetylases which mediate the gene silencing, as TSA does not affect CpG methylation (30).

Therefore, the conclusion is that variable methylation of the PAI-1 gene 5'-flanking region in different cell lines, rather than methylation of an upstream $\mathrm{CpG}$ island, is inversely correlated with variable transcription of the $P A I-1$ gene. Thus, methylation of PAI-1 5'-flanking region may be another example of tissue specific patterns of methylation, following the maspin and $M C J$ genes $(11,12)$. However, different methylation of the 5 '-flanking region could not explain the different PAI-1 mRNA levels in Hep2 and HT-1080 cells, indicating that other, transcriptional or post-transcriptional regulatory mechanisms are equally important in determining the PAI-1 mRNA levels. Our present findings are particularly relevant for the elucidation of the types of abnormal transcriptional regulation which leads to overexpression of components of the plasminogen activation system in cancers. Our preliminary results on oral squamous cell carcinomas indicate that variation in CpG methylation of the PAI-1 gene 5'-flanking region may well contribute to the higher expression of PAI-1 in tumours than in the corresponding normal tissue. In a number of recent papers, the role of $\mathrm{CpG}$ methylation for expression of uPA in breast and prostate tumours have been reported, the focus being the expression of uPA by the malignant cells themselves $(22,23)$. However, it is important to realise that both uPA and PAI-1 in tumours are expressed by a variety of cell types. In breast tumours, the predominant uPA and PAI-1 expressing cell type are in fact stromal cells $(7,40)$, while in oral cancers, the predominant PAI-1 expressing cell type are the malignant cells themselves (41). An elucidation of the genetic, epigenetic and other regulatory mechanisms determining the expression of PAI-1 in different cell types in tumours is therefore a particularly interesting challenge.

\section{Acknowledgements}

We would like to thank Professor Erik Dabelsteen, School of Dentistry, University of Copenhagen and Professor Per Guldberg, Institute of Cancer Biology, Danish Cancer Society, for their critical review of the manuscript; and Shiliang Ma and Søren Peter Jonstrup, Department of Molecular Biology, University of Aarhus, for practical help; as well as all members of our laboratory for their daily assistance. 


\begin{abstract}
Abbreviations
AML: acute myeloid leukemia; CTF/NF1: CCAAT-binding transcription factor/ nuclear factor-1; DMEM: Dulbecco's modified Eagle's medium; ERE: estrogen response element; FBS: fetal bovine serum; FMS: the frequency of methylated $\mathrm{CpG}$ sites; FTM: the frequency of total methylated CpGs; GAPDH, glyceraldehyde 3-phosphate dehydrogenase; HRE, hypoxia-responsive element; hTERT: human telomerase reverse transcriptase; IL-4: interleukin-4; $M A O B$ : human monoamine oxidase B; $M C J$ : the
\end{abstract}

methylation controlled DNAJ gene; MDR1: the multidrug resistance 1 gene; MSP: methylation-specific PCR; PAI-1: plasminogen activator inhibitor-1; RT-PCR: reverse transcription PCR; tPA: tissue-type plasminogen activator; TSA: trichostatin A; uPA: urokinase-type plasminogen activator; VLDLRE: very low density lipoprotein-responsive element; 5-aza-CdR: 5-aza-2'- deoxycytidine.

\section{References}

1. Wind T, Hansen M, Jensen JK et al. The molecular basis for anti-proteolytic and non-proteolytic functions of plasminogen activator inhibitor type-1: roles of the reactive centre loop, the shutter region, the flexible joint region and the small serpin fragment. Biol Chem 2002; 383: 21-36.

2. Andreasen PA, Egelund R, Petersen HH. The plasminogen activation system in tumor growth, invasion, and metastasis. Cell Mol Life Sci 2000; 57: 25-40.

3. Vaughan DE. Angiotensin and vascular fibrinolytic balance. Am J Hypertens 2002; 15: 3S-8S.

4. Durand MK, Bodker JS, Christensen A et al. Plasminogen activator inhibitor-I and tumour growth, invasion, and metastasis. Thromb Haemost 2004; 91: 438-49.

5. Nagamine Y, Medcalf RL, Munoz-Canoves P. Transcriptional and posttranscriptional regulation of the plasminogen activator system. Thromb Haemost 2005; 93: 661-75.

6. Alessi MC, Juhan-Vague I. Contribution of PAI-1 in cardiovascular pathology. Arch Mal Coeur Vaiss 2004; 97: 673-8.

7. Offersen BV, Nielsen BS, Hoyer-Hansen G et al. The myofibroblast is the predominant plasminogen activator inhibitor-1-expressing cell type in human breast carcinomas. Am J Pathol 2003; 163: 1887-99.

8. Illemann M, Hansen U, Nielsen HJ et al. Leadingedge myofibroblasts in human colon cancer express plasminogen activator inhibitor-1. Am J Clin Pathol 2004; 122: 256-65.

9. Usher PA, Thomsen OF, Iversen P et al. Expression of urokinase plasminogen activator, its receptor and type-1 inhibitor in malignant and benign prostate tissue. Int J Cancer 2005; 113: 870-80.

10. Attwood JT, Yung RL, Richardson BC. DNA methylation and the regulation of gene transcription. Cell Mol Life Sci 2002; 59: 241-57.

11. Futscher BW, Oshiro MM, Wozniak RJ et al. Role for DNA methylation in the control of cell type specific maspin expression. Nat Genet 2002; 31: 175-9.

12. Strathdee $G$ et al. Cell type-specific methylation of an intronic $\mathrm{CpG}$ island controls expression of the MCJ gene. Carcinogenesis 2004; 25: 693-701.

13. Esteller M. Cancer epigenetics: DNA methylation and chromatin alterations in human cancer. Adv Exp Med Biol 2003; 532: 39-49.

14. Baylin SB, Herman JG. DNA hypermethylation in tumorigenesis: epigenetics joins genetics. Trends Genet 2000; 16: 168-74.

15. Shen L, Fang J, Qiu D et al. Correlation between DNA methylation and pathological changes in human hepatocellular carcinoma. Hepatogastroenterology 1998; 45: 1753-9.

16. Hanada $\mathrm{M}$ et al. bcl-2 gene hypomethylation and high-level expression in B-cell chronic lymphocytic leukemia. Blood 1993; 82: 1820-8.

17. Gupta A, Godwin AK, Vanderveer L et al. Hypomethylation of the synuclein gamma gene $\mathrm{CpG}$ island promotes its aberrant expression in breast carcinoma and ovarian carcinoma. Cancer Res 2003; 63: 664-73.

18. Wong WK, Chen K, Shih JC. Decreased methylation and transcription repressor $\mathrm{Sp} 3$ up-regulated human monoamine oxidase (MAO) B expression during Caco-2 differentiation. J Biol Chem 2003; 278: 36227-35.

19. Chicoine E, Esteve PO, Robledo O et al. Evidence for the role of promoter methylation in the regulation of MMP-9 gene expression. Biochem Biophys Res Commun 2002; 297: 765-72.

20. Nakayama M, Wada M, Harada T et al. Hypomethylation status of $\mathrm{CpG}$ sites at the promoter region and overexpression of the human MDR1 gene in acute myeloid leukemias. Blood 1998; 92: 4296-307.

21. De Smet C, De Backer O, Faraoni I et al. The activation of human gene MAGE-1 in tumor cells is correlated with genome-wide demethylation. Proc Natl Acad Sci U.S.A 1996; 93: 7149-53.

22. Pakneshan P, Xing RH, Rabbani SA. Methylation status of uPA promoter as a molecular mechanism regulating prostate cancer invasion and growth in vitro and in vivo. FASEB J 2003; 17: 1081-8.

23. Xing RH, Rabbani SA. Transcriptional regulation of urokinase (uPA) gene expression in breast cancer cells: role of DNA methylation. Int J Cancer 1999; 81 : 443-50.

24. Lund LR, Georg B, Nielsen LS et al. Plasminogen activator inhibitor type 1: cell-specific and differentiation-induced expression and regulation in human cell lines, as determined by enzyme-linked immunosorbent assay. Mol Cell Endocrinol 1988; 60: 43-53.

25. Worm J, Bartkova J, Kirkin AF et al. Aberrant p27Kip1 promoter methylation in malignant melanoma. Oncogene 2000; 19: 5111-5.

26. Gao $\mathrm{S}$ et al. Genetic and epigenetic alterations of the blood group ABO gene in oral squamous cell carcinoma. Int J Cancer 2004; 109: 230-7.

27. Klinger $\mathrm{KW}$ et al. Plasminogen activator inhibitor type 1 gene is located at region q21.3-q22 of chromosome 7 and genetically linked with cystic fibrosis. Proc Natl Acad Sci U.S.A 1987; 84: 8548-52.

28. Irigoyen JP, Munoz-Canoves P, Montero L et al. The plasminogen activator system: biology and regulation. Cell Mol Life Sci 1999; 56: 104-32.

29. Riccio A, Lund LR, Sartorio R et al. The regulatory region of the human plasminogen activator inhibitor type-1 (PAI-1) gene. Nucleic Acids Res 1988; 16: 2805-24.

30. Cameron EE, Bachman KE, Myohanen $\mathrm{S}$ et al. Synergy of demethylation and histone deacetylase inhibition in the re-expression of genes silenced in cancer. Nat Genet 1999; 21: 103-7.

31. Gonzalez-Zulueta M, Bender CM, Yang AS et al. Methylation of the $5^{\prime} \mathrm{CpG}$ island of the p16/CDKN2 tumor suppressor gene in normal and transformed human tissues correlates with gene silencing. Cancer Res 1995; 55: 4531-5.
32. Guilleret I, Benhattar J. Unusual distribution of DNA methylation within the hTERT CpG island in tissues and cell lines. Biochem Biophys Res Commun 2004; 325: 1037-43.

33. Bender $\mathrm{CM}$ et al. Roles of cell division and gene transcription in the methylation of $\mathrm{CpG}$ islands. Mol Cell Biol 1999; 19: 6690-8.

34. Nguyen C, Liang G, Nguyen TT et al. Susceptibility of nonpromoter $\mathrm{CpG}$ islands to de novo methylation in normal and neoplastic cells. J Natl Cancer Inst 2001 93: 1465-72.

35. Makar KW, Perez-Melgosa M, Shnyreva M et al. Active recruitment of DNA methyltransferases regulates interleukin 4 in thymocytes and T cells. Nat Immunol 2003; 4: 1183-90.

36. Pogribny IP, Pogribna M, Christman JK et al. Single-site methylation within the $\mathrm{p} 53$ promoter region reduces gene expression in a reporter gene construct: possible in vivo relevance during tumorigenesis Cancer Res 2000; 60: 588-94.

37. Jones PA, Takai D. The role of DNA methylation in mammalian epigenetics. Science 2001; 293: 1068-70.

38. Keeton MR, Curriden SA, van Zonneveld AJ et al. Identification of regulatory sequences in the type 1 plasminogen activator inhibitor gene responsive to transforming growth factor beta. J Biol Chem 1991; 266: 23048-52.

39. Rice JC, Allis CD. Histone methylation versus histone acetylation: new insights into epigenetic regulation. Curr Opin Cell Biol 2001; 13: 263-73.

40. Nielsen BS, Sehested M, Timshel S et al. Messenger RNA for urokinase plasminogen activator is expressed in myofibroblasts adjacent to cancer cells in human breast cancer. Lab Invest 1996; 74: 168-77.

41. Nozaki S, Endo Y, Kawashiri S et al. Immunohistochemical localization of a urokinase-type plasminogen activator system in squamous cell carcinoma of the oral cavity: association with mode of invasion and lymph node metastasis. Oral Oncol 1998; 34: 58-62.

42. Hou B, Eren M, Painter CA et al. Tumor necrosis factor alpha activates the human plasminogen activator inhibitor-1 gene through a distal nuclear factor kappaB site. J Biol Chem 2004; 279: 18127-36.

43. Fink T, Kazlauskas A, Poellinger L et al. Identification of a tightly regulated hypoxia-response element in the promoter of human plasminogen activator inhibitor-1. Blood 2002; 99: 2077-83.

44. Eriksson P, Nilsson L, Karpe F et al. Very-low-density lipoprotein response element in the promoter region of the human plasminogen activator inhibitor-1 gene implicated in the impaired fibrinolysis of hypertriglyceridemia. Arterioscler Thromb Vasc Biol 1998; 18: $20-6$.

45. Dennler S, Itoh S, Vivien D et al. Direct binding of Smad3 and Smad4 to critical TGF beta-inducible elements in the promoter of human plasminogen activator inhibitor-type 1 gene. EMBO J 1998; 17: 3091-100. 